\title{
The Effect of Shoulder Abduction and Medial Epicondylectomy on Ulnar Nerve Strain: A Preliminary Study
}

\author{
Carla G. Barberio, Tahseen Chaudhry', Dominic M. Power1, Bernard M. Lawless², Daniel M. Espino², Simon Tan'1, Joanne C. Wilton \\ Department of Anatomy, College of Medical and Dental Sciences, University of Birmingham, ${ }^{1}$ Hand and Peripheral Nerve Research Network, Birmingham Hand Centre, \\ Queen Elizabeth Hospital, University of Birmingham, ${ }^{2}$ Department of Mechanical Engineering, University of Birmingham, Birmingham, United Kingdom
}

\section{AbSTRaCT}

Objectives: The primary aim was to determine whether a dynamic suture marker method of measuring ulnar nerve strain yields comparable results to strain gauges. The secondary aim was to assess the effect of elbow flexion, shoulder abduction and medial epicondylectomy on strain. Methods: In four embalmed elbows, ulnar nerve strain was measured using suture markers during elbow flexion and shoulder abduction before and after medial epicondylectomy. Linear regression analysis and Wilcoxon signed-rank test were used to analyse the results. Results: Ulnar nerve strain increased in direct proportion to elbow flexion angle before and after medial epicondylectomy, with one exception. At $90^{\circ}$ shoulder abduction, strain was $0 \%-17 \%$. Strain was greatest at $90^{\circ}$ and least at $110^{\circ}$ before and after medial epicondylectomy, $P>0.05$. The effect of medial epicondylectomy varied. Strain was reduced at $90^{\circ}$ by $5 \%$, at $110^{\circ}$ by $0 \%$ and at $120^{\circ}$ by $1 \% ; P>0.05$. Conclusions: The suture marker method yielded comparable results to strain gauges. Both shoulder abduction and medial epicondylectomy did not have statistically significant effects on ulnar nerve strain. However, only four embalmed elbows were studied in this preliminary study, so a large difference would be needed to produce a significant change. The finding that medial epicondylectomy fails to reduce strain raises questions about its role in treating cubital tunnel syndrome and highlights the need for further research. The authors believe that the technique described for dynamic strain assessment is applicable in an in vivo setting and therefore, should be used to compare strain properties of cadaveric and in vivo nerves.

Keywords: Cubital tunnel syndrome, elbow, shoulder, sutures, ulnar nerve

\section{INTRODUCTION}

Cubital tunnel syndrome is the most prevalent neuropathy of the ulnar nerve. One in 78 people are affected by this syndrome, which can have a significant impact on the quality of life. ${ }^{[1,2]}$ It is postulated that its anatomical position (posterior to the medial epicondyle and the axis of elbow flexion) puts the nerve at risk of exposure to abnormal forces. These forces result in an increased propensity for nerve injury. ${ }^{[3]}$ The aetiology of cubital tunnel syndrome is controversial. Originally, it was thought to be due to a compressive or entrapment neuropathy. ${ }^{[4-6]}$ However, more recently, it has been thought to be due to nerve strain. ${ }^{[3,7-9]}$ At certain levels of strain, nerve perfusion and conduction have been found to be reduced or arrested. ${ }^{[10-13]}$ It has previously been shown that, during the normal movement range, the ulnar nerve reaches these levels of strain. ${ }^{[9,14]}$ As ulnar nerve strain values have been proven to be so variable, there is a need for more research into this area. ${ }^{[15]}$ While the effect of elbow flexion on strain is understood, research on the

\begin{tabular}{|l|l|}
\hline \multicolumn{2}{|c|}{ Access this article online } \\
\hline Quick Response Code: & Website: \\
\hline & www.journalmsr.com \\
\cline { 2 - 2 } & \\
\hline
\end{tabular}

effect of shoulder abduction ${ }^{[15]}$ and medial epicondylectomy is lacking and has not been studied sufficiently.

The three current surgical management strategies in common use are in situ decompression, anterior transpositions and medial epicondylectomy. In contrast to in situ decompression, medial epicondylectomy and anterior transposition have a theoretical advantage of addressing abnormal strain as well as compression of the nerve. However, there is a paucity of literature on whether this is the case for medial epicondylectomy. To date, the effect of medial

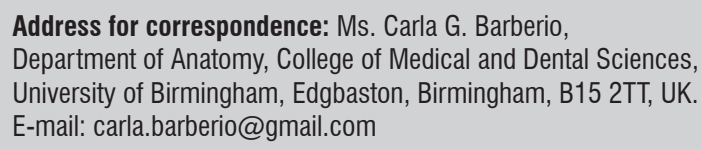

Received : 18-12-2018

Revised : 01-01-2019

Accepted : 11-01-2019

Published Online : 18-02-2019

This is an open access journal, and articles are distributed under the terms of the Creative Commons Attribution-NonCommercial-ShareAlike 4.0 License, which allows others to remix, tweak, and build upon the work non-commercially, as long as appropriate credit is given and the new creations are licensed under the identical terms.

For reprints contact: reprints@medknow.com

How to cite this article: Barberio CG, Chaudhry T, Power DM, Lawless BM, Espino DM, Tan S, et al. The effect of shoulder abduction and medial epicondylectomy on ulnar nerve strain: A preliminary study. J Musculoskelet Surg Res 2019;3:134-40. 
epicondylectomy on ulnar nerve strain has only been studied using strain gauges. ${ }^{[16-18]}$ Unlike the suture marker method, these cannot be used intraoperatively as their implantation damages the nerve and therefore, an intraoperative assessment of strain reduction cannot be performed. Clearly, the potential to translate a strain measurement technique into clinical practice may directly improve patient outcomes.

The biomechanics of the ulnar nerve in elbow flexion with concomitant shoulder abduction has not been previously studied. This study aims to fill this gap in the current knowledge. To date, only strain gauges have been used to take dynamic measurements. ${ }^{[8,9,14,19,20]}$ However, this study aims to take dynamic measurements by videoing the suture marker method, instead of static measurements from photographs. This will provide results that are more applicable to a real-life situation, which eliminate the effect of stress relaxation. Therefore, the first aim of this study is to assess whether a dynamic manner of measuring strain from the suture marker method yields comparable results to those from a strain gauge as available in literature. The second aim is to assess the effect of elbow flexion, shoulder abduction and medial epicondylectomy on ulnar nerve strain.

\section{Materials And Methods}

\section{Baseline characteristics}

This study was performed on four embalmed upper limbs, from three cadavers aged 75-90 years with a mean age of 85 years. There were no known histories of cubital tunnel syndrome or handedness, cubitus varus or previous trauma to the nerve, elbow, shoulder or neck.

\section{Dissection procedure}

All nerves were exposed in a standard fashion. ${ }^{[18,21-24]}$ The olecranon, medial epicondyle and ulnar nerve were palpated and marked. A 15-cm skin incision was then made, centred on the cubital tunnel. Subcutaneous tissue was dissected until fascia superficial to the ulnar nerve was visible. The deep fascia was divided along the course of the nerve. Superficial and deep fasciae of flexor carpi ulnaris were divided, ${ }^{[7,23]}$ followed by separation of its two heads along the normal cleavage planes. To mimic an in vivo environment, no blood vessels overlying the nerve were removed, nerve branches were left intact and neurolysis was not conducted. ${ }^{[9]}$

In situ decompression was performed from the medial intermuscular septum to the first motor branch to flexor carpi ulnaris after releasing Struthers' ligament, the medial intermuscular septum, the cubital tunnel retinaculum and Osborne's ligament. The paraneurium was not disturbed, and the nerve was neither moved nor disconnected from its original bed.

Evidence of anconeus epitrochlearis was found in one arm; this was divided to avoid any confounding effect of additional nerve compression or entrapment. No nerves subluxed or dislocated out of the retrocondylar groove during passive motion of the elbow and shoulder.

\section{Strain measurement}

A pilot study was initially conducted on two porcine forelimbs to confirm the suitability of this method. These were supplied by Dissect (Birmingham, UK). Similar to other studies, ${ }^{[7,15,22-24]}$ two 4-0 proline sutures were placed proximal to the cubital tunnel into the epineurium to avoid injuring the nerve or leaving it susceptible to tearing. Epineurial elongation was used as a measure of intraneural elongation of the ulnar nerve. ${ }^{[7,15,22,25]}$ Sutures were placed approximately $2 \mathrm{~cm}$ apart, with the arm placed in the neutral position (shoulder abduction $90^{\circ}$ and elbow at maximum extension). Surgical reference rulers were pinned onto the surrounding tissue to allow subsequent calibration.

All cadavers were supine with the head, neck, wrist and fingers in neutral positions and the forearm supinated. Each limb was then ranged through $0^{\circ}-120^{\circ}$ elbow flexion at $90^{\circ}, 110^{\circ}$ and $120^{\circ}$ shoulder abduction in order to portray the whole range of elbow movement and to investigate the angles of shoulder abduction previously unstudied [Table 1]. Shoulder abduction angles were selected based on pilot data and the mobility of the cadavers. A goniometer was used to position the shoulder and elbow angles. For repeatability, lines of $90^{\circ}, 110^{\circ}$ and $120^{\circ}$ shoulder abduction were drawn on the arms and aligned with a mounted laser to ensure that the correct angles were maintained during elbow flexion.

Videos were taken of the nerve of the full range of elbow movement at all shoulder positions with a Sony HDR-PJ780VE camera (Sony Corporation, Tokyo, Japan). To avoid parallax errors, images were taken with the camera perpendicular to the plane of the medial surface of the nerve. It has been shown that tensile stress reduces over time due to stress relaxation properties of viscoelastic human nerves, ${ }^{[26]}$ therefore, no repeats were performed to avoid this confounding effect.

\section{Medial epicondylectomy}

The anterior face of the medial epicondyle was exposed. Attention was given to preserving the periosteal layer, which acted as an interface with the nerve epineurium; thus, no additional dissection of the ulnar nerve was required. The medial epicondyle was then removed using a CleanCut ${ }^{\mathrm{TM}}$ CNS3 oscillating saw (De Soutter Medical Limited, Buckinghamshire, United Kingdom) at 14,000 rpm.

\begin{tabular}{lcc}
\hline $\begin{array}{l}\text { Table 1: Ulnar nerve strain at different angles of shoulder } \\
\text { abduction }\left(90^{\circ}, 110^{\circ} \text { and } 120^{\circ}\right) \\
\text { epicondylectomy }\end{array}$ \\
$\begin{array}{lcc}\text { Shoulder } \\
\text { abduction }\left({ }^{\circ}\right)\end{array}$ & \multicolumn{2}{c}{ Strain (\%) } \\
\cline { 2 - 3 } & Before ME & After ME \\
\hline 90 & 14 & 8 \\
110 & 6 & 3 \\
120 & 7 & 7 \\
\hline
\end{tabular}

ME: Medial epicondylectomy 
Barberio, et al.

A composite sagittal and coronal plane cut was used to enable the nerve to glide anteriorly without impingement. The standard partial medial epicondylectomy technique as described in previous studies ${ }^{[18,27]}$ was followed. This adapted technique avoids removal of the medial collateral ligament and common flexor origin and therefore, is less invasive and does not risk elbow instability or cubital valgus unlike other techniques such as the distal medial epicondylectomy. ${ }^{[18]}$

Following medial epicondylectomy, each limb was again ranged through the different configurations of shoulder abduction and elbow flexion angles (see strain measurement section, above). As performed when intact, video recordings were taken of each ulnar nerve during shoulder abduction and elbow flexion so as to measure nerve strain following the procedure.

\section{Video analysis}

Videos were analysed using ImageJ and Fiji software (National Institutes of Health, Bethesda, MD, USA) ${ }^{[28,29]}$ with the MTrackJ plugin. ${ }^{[30]}$ Rulers attached to arm musculature were used to calibrate the scale. The positions of the sutures proximal to the tunnel were then tracked at ten frame intervals. Strain was then calculated (Equation 1).

$\varepsilon=\frac{L-l_{o}}{l_{o}}$

Where $\varepsilon$ is strain, $l_{o}$ is the original length $(\mathrm{mm})$ and $L$ is the final length (mm).

\section{Statistical analysis}

Linear regression was performed to analyse the relationship between elbow flexion angle and ulnar nerve strain. A Wilcoxon signed-rank test was used to assess whether there was a significant difference $(P<0.05)$ in ulnar nerve strain between different angles of shoulder abduction and between before and after medial epicondylectomy at full elbow flexion $\left(120^{\circ}\right)$. The pairs of data analysed were before and after medial epicondylectomy. The elbow flexion was standardised at $120^{\circ}$, so the effect of shoulder abduction and medial epicondylectomy could be investigated.

\section{Results}

With one exception, due to missing data, ulnar nerve strain proximal to the cubital tunnel increased in direct proportion to the elbow flexion angle before and after medial epicondylectomy [Figures 1-3]. At 100\% elbow flexion, strain was greatest at $90^{\circ}$ shoulder abduction and least at $110^{\circ}$ shoulder abduction before and after medial epicondylectomy. However, these strains were not statistically significantly different $[P>0.05$; Table 1].

The effect of medial epicondylectomy varied among and between individual limbs. Medial epicondylectomy reduced ulnar nerve strain at $90^{\circ}$ shoulder abduction in three specimens; at $110^{\circ}$ in one specimen and at $120^{\circ}$ in one specimen [Figures 1a-c, 2b and 3a].

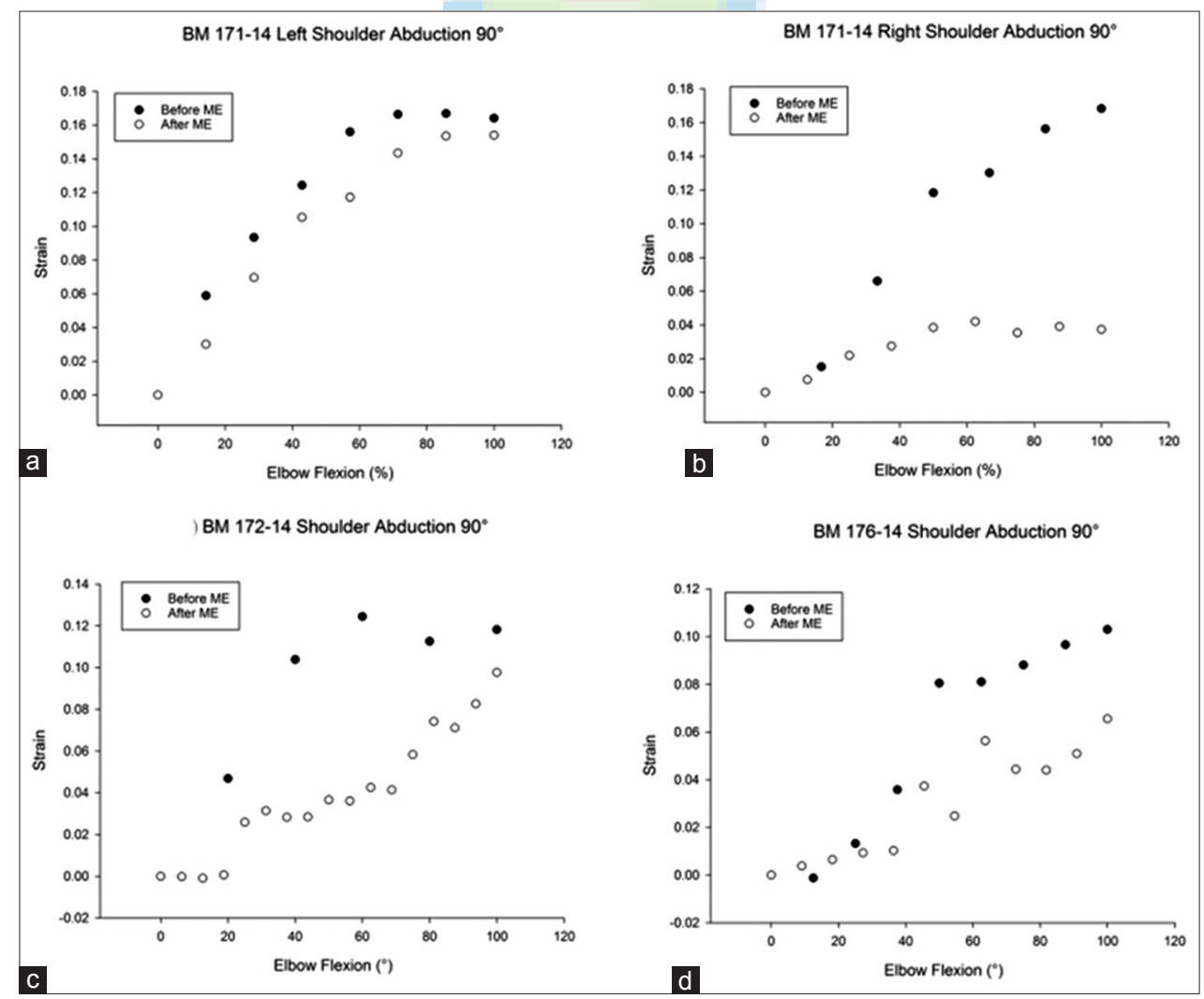

Figure 1: Elbow flexion (\%) versus proximal ulnar nerve strain at $90^{\circ}$ shoulder abduction from dynamic data before and after medial epicondylectomy. a) Cadaver 1: BM 171-14 left elbow; b) Cadaver 1: BM 171-14 right elbow; c) Cadaver 2: BM 172-14; and d) Cadaver 3 BM 176-14 
Shoulder abduction, ME and ulnar nerve strain
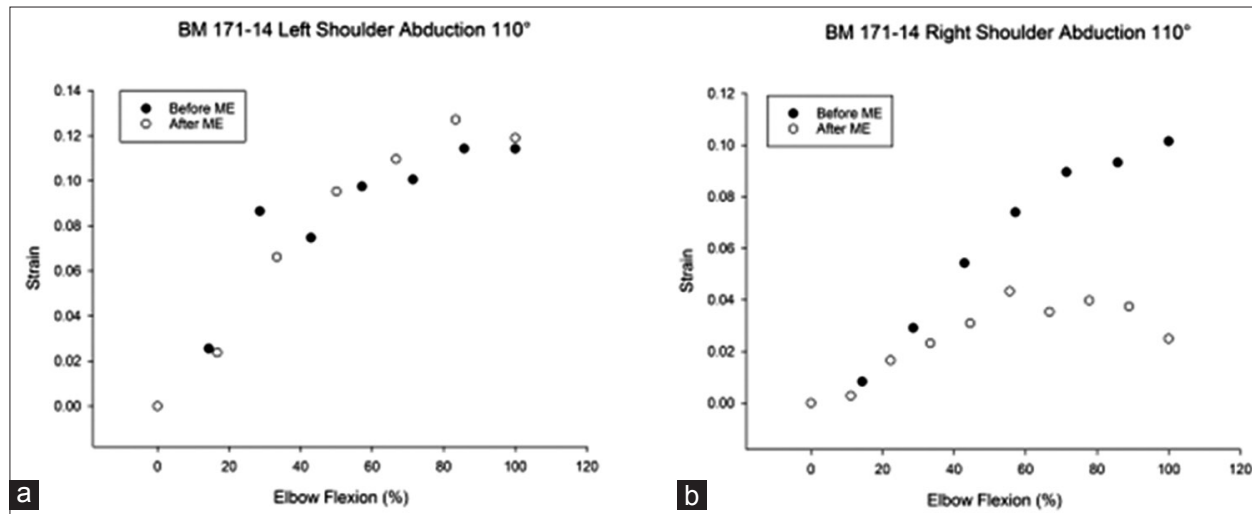

BM 172-14 Shoulder Abduction 110
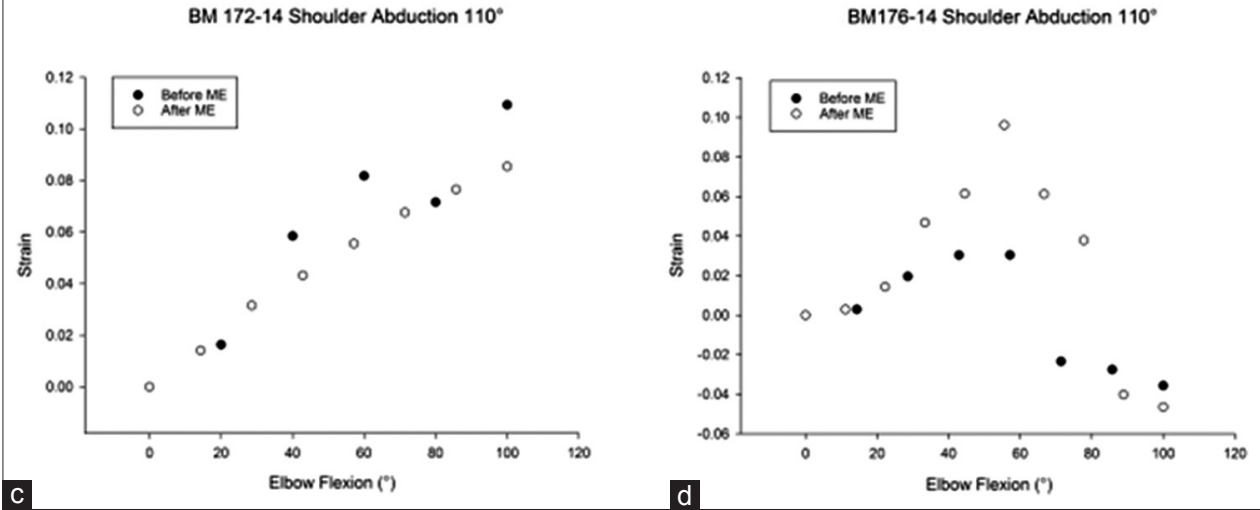

Figure 2: Elbow flexion (\%) versus proximal ulnar nerve strain at $110^{\circ}$ shoulder abduction from dynamic data before and after medial epicondylectomy. a) Cadaver 1: BM 171-14 left elbow; b) Cadaver 1: BM 171-14 right elbow; c) Cadaver 2: BM 172-14; and d) Cadaver 3 BM $176-14$

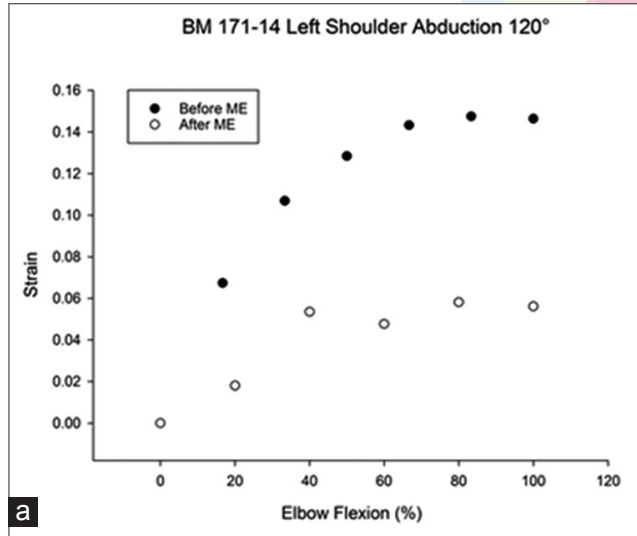

BM 172-14 Shoulder Abduction $120^{\circ}$

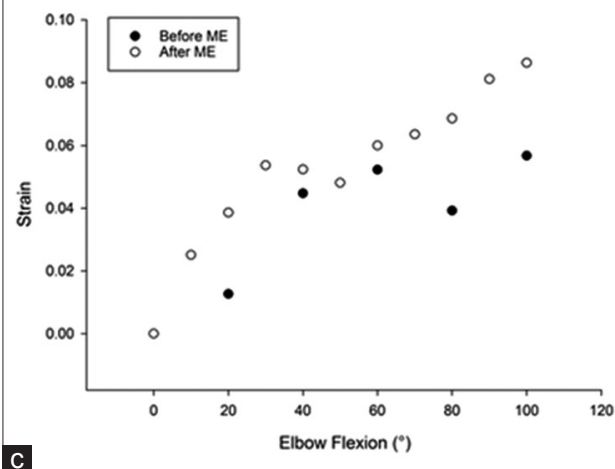

BM 171-14 Right Shoulder Abduction $120^{\circ}$

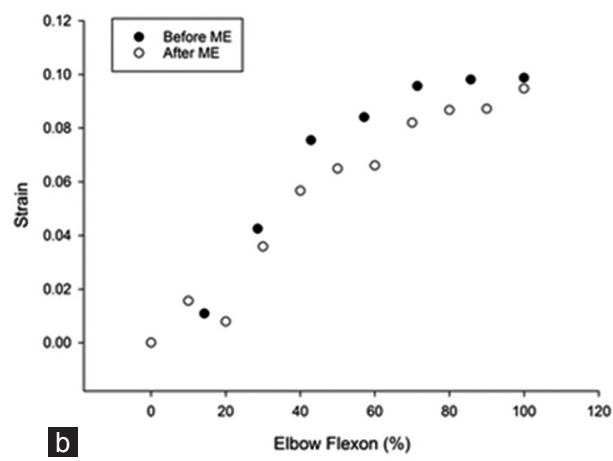

BM 176-14 Shoulder Abduction $120^{\circ}$

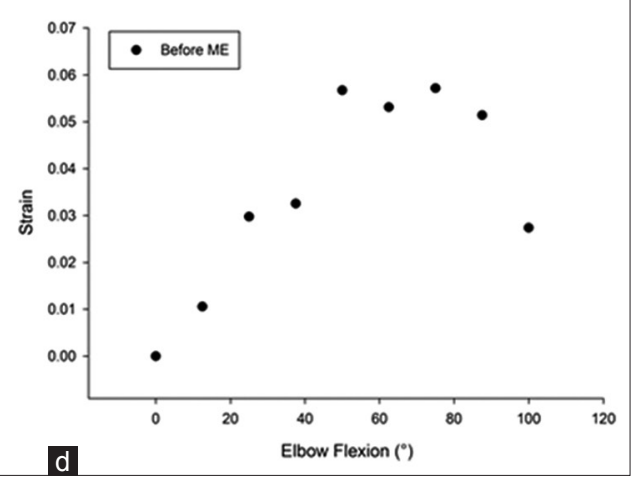

Figure 3: Elbow flexion (\%) versus proximal ulnar nerve strain at $120^{\circ}$ shoulder abduction from dynamic data before and after medial epicondylectomy. a) Cadaver 1: BM 171-14 left elbow; b) Cadaver 1: BM 171-14 right elbow; c) Cadaver 2: BM 172-14; and d) Cadaver 3 BM $176-14$ 
Barberio, et al.

Similarly, medial epicondylectomy reduced ulnar nerve strain at greater percentages of elbow flexion in one specimen at $90^{\circ}$ shoulder abduction and one specimen at $120^{\circ}$ shoulder abduction [Figures 1d and 3b].

For one specimen at $120^{\circ}$ after medial epicondylectomy, data could not be obtained as sutures 1 and 2 were not captured in the video [Figure 3d].

However, in two other specimens after medial epicondylectomy, there was increased strain [Figures $2 \mathrm{~d}$ and $3 \mathrm{c}$ ] or approximately the same strain in the final two specimens [Figures $2 \mathrm{a}$ and $\mathrm{c}$ ].

Mean maximum strain at $90^{\circ}$ before medial epicondylectomy was $14 \%$ and after medial epicondylectomy was $9 \%$, with a range from $0 \%$ to $17 \%$ before and $0 \%$ to $15 \%$ after medial epicondylectomy. At $110^{\circ}$, mean maximum strain was $9 \%$ before and after medial epicondylectomy. At $120^{\circ}$, mean maximum strain was $9 \%$ before medial epicondylectomy compared to $8 \%$ after medial epicondylectomy. Hence, reduction of $5 \%, 0 \%$ and $1 \%$ was observed at $90^{\circ}, 110^{\circ}$ and $120^{\circ}$, respectively. Figure 1 clearly shows that proximal ulnar nerve strain decreased for all four arms at $90^{\circ}$.

No significant difference was observed between before and after medial epicondylectomy at all shoulder abduction angles at $100 \%$ elbow flexion $[P>0.05$; Figure 4$]$.

\section{Discussion}

Cubital tunnel syndrome is the most prevalent neuropathy of the ulnar nerve. ${ }^{[3]}$ Historically, it was thought that cubital tunnel syndrome was due to nerve compression and entrapment. ${ }^{[4]}$ More recently, it is accepted that its pathophysiology is multifactorial, with compression, entrapment, excursion and strain hypothesised to contribute in pathologic synergy.

Medial epicondylectomy is used to treat cubital tunnel syndrome, but evidence on whether it alleviates symptoms

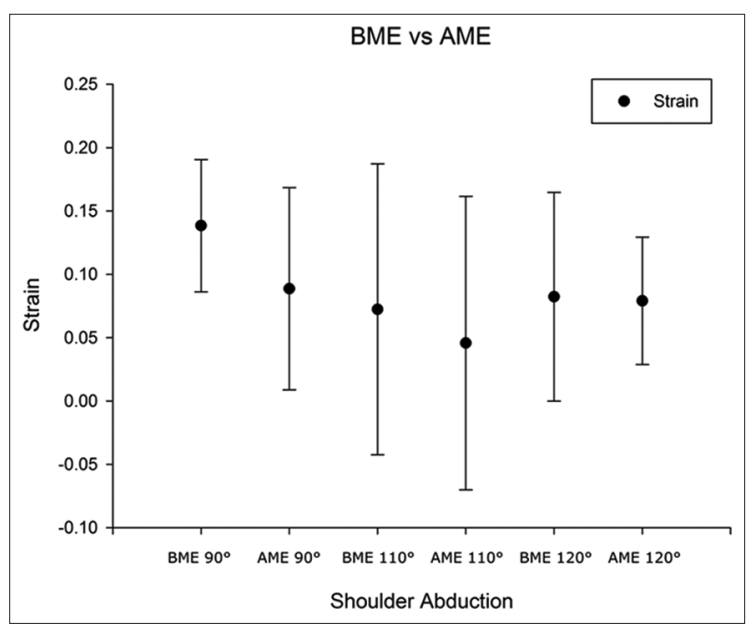

Figure 4: Strain of the ulnar nerve proximal to the cubital tunnel, at $120^{\circ}(100 \%)$ elbow flexion, for the different shoulder abduction angles between before (BME) and after (AME) medial epicondylectomy by reducing nerve strain is lacking and has previously only be measured by strain gauges, which cannot be used clinically. ${ }^{[16-18,25,27,31]}$

In addition to the effect of elbow flexion and medial epicondylectomy on strain, this study has tested the effect of shoulder abduction, which has not been previously investigated. A novel method of measuring nerve strain was also used. To the authors' knowledge, the use of a videoed suture method has not been previously described. The rationale for using video was to try to eliminate the effects of stress relaxation. The degree of stress relaxation is determined by the time over which the stress is induced. With photography, time elapses between setting the limb to the correct position and capturing the photograph from which the strain is measured. This is a possible source of error, with natural variation between each photograph. However, with videoing, the strain is measured at the exact time that the limb was positioned. We hoped that a single controlled cycle of dynamic assessment would reduce the error from stress relaxation. A dynamic representation also more accurately reflects the in vivo situation. This study compared ulnar nerve strain proximal to the cubital tunnel at different degrees of shoulder abduction and elbow flexion before and after medial epicondylectomy to investigate whether medial epicondylectomy relieves symptoms by relieving nerve strain.

Schuind et al..$^{[7]}$ and Toby and Hanesworth ${ }^{[8]}$ also measured cadaveric nerve strain at $90^{\circ}$ shoulder abduction and found similar values of $18 \%$ and $0 \%-14 \%$, respectively, which again is comparable to the range $(0 \%-17 \%)$ found in the current study. One study measured strain at $100^{\circ}$ shoulder abduction ${ }^{[20]}$ and found $3 \%$ strain. Another study measured strain at $110^{\circ}$ shoulder abduction and found $6 \%$ strain; $;{ }^{[9]}$ this is comparable to the present study ( $6 \%$ strain at $110^{\circ}$ shoulder abduction).

At $100 \%$ elbow flexion, medial epicondylectomy was found to reduce proximal ulnar nerve strain at $90^{\circ}$ shoulder abduction by $5 \%$, at $110^{\circ}$ shoulder abduction by $2.5 \%$ and at $120^{\circ}$ shoulder abduction by $0.5 \%$. However, none of these differences were significant. This reflects what is observed clinically as medial epicondylectomy works better for some patients than for others. Two other studies found similar strain reductions of $4.8 \%$ in embalmed arms ${ }^{[16]}$ and $2.5 \%$ in fresh arms following medial epicondylectomy. ${ }^{[18]}$ These results were both significant. Mitchell et al..$^{[17]}$ measured a reduction of $5.1 \%$ in fresh arms, which like the present study, was not statistically significant. These studies measured strain with strain gauges, which involve damaging the nerve and altering the biomechanics. The dynamic suture marker method does not damage the nerve. Therefore, the authors were encouraged by the fact that this study, using a dynamic and less invasive method of measuring strain, yielded similar results to those from strain gauges. The method described in the present study could be used in vivo. Therefore, it has the potential for use intraoperatively to immediately assess operation outcomes. If it is agreed that strain contributes to cubital tunnel syndrome, it could perhaps be useful to 
measure whether an operation (e.g., in situ decompression) has reduced nerve strain intraoperatively to see if further intervention (e.g., transposition/epicondylectomy) is required while the patient is still on the operating table. Measuring strain intraoperatively could therefore save the time, money and resources required to bring patients back to theatre if the original operation did not reduce the nerve strain.

Obtaining similar results, despite differences in specimen types and methodology, is promising for the validity of the current study. However, this study is not without limitations. First, biomechanical properties of cadaveric nerves may contrast to those of live nerves. ${ }^{[9,26]}$ Despite this, measuring ulnar nerve strain in cadaveric arms is a well-established protocol. ${ }^{[6-9,14,16-18,23]}$ Although absolute tensile forces may be higher in embalmed cadaveric nerves, a positive correlation has been proven between unembalmed and embalmed specimens. ${ }^{[32]}$ Second, only four arms were available at the time of testing, which is a suboptimal sample size that could explain the lack of statistical significance. However, as extremely similar results have been observed in other studies, there is no reason to believe that the current study's results are not representative.

An alternate explanation for the lack of a statistically significant strain reduction could be that medial epicondylectomy works better for some patients than for others due to variable nerve strains. However, it may only take a small variation in strain to produce symptoms in certain patients. Other patients may be more resistant to developing a problem from small strain changes. As this was a cadaveric study, it does not correlate with any symptoms of clinical outcomes. It would be useful to have clinical data to complement this research as well as physiological parameters such as nerve oxygenation and perfusion; these could be prime areas for future research. It would also be interesting to investigate the effects of other joint positions on ulnar nerve strain.

A study investigating patient outcomes after medial epicondylectomy found that fair and poor improvement was observed in 4 of the 25 patients $(16 \%)$ studied; ${ }^{[31]}$ this could be due to the variable reductions in strain seen with medial epicondylectomy. A high variation between nerves has been observed in many studies other than the current one, but the explanation for this is unknown. ${ }^{[7,8,33]}$ This extensive range of strains might be the cause of the variation of outcomes in the clinical environment. ${ }^{[8]}$ Young's modulus was not investigated in this study as it does not give a full understanding of the behaviour of viscoelastic tissues such as the ulnar nerve. ${ }^{[34]}$

Mostly, medial epicondylectomy results in symptomatic relief for patients. ${ }^{[27,31,35-40]}$ Hence, it is likely that multiple factors contribute to cubital tunnel syndrome. These factors do include strain, but also compression, entrapment, excursion and other as yet undefined influences which work together in pathologic synergy. The authors acknowledge that there are clear limitations of this study. In spite of the small sample size, missing data and use of embalmed cadaveric nerves, this study provokes some interesting questions, which need to be addressed with future larger cadaveric and clinical studies to further understand the behaviour of the ulnar nerve.

\section{Conclusions}

The suture marker method yielded comparable results to strain gauges. Both shoulder abduction and medial epicondylectomy did not have statistically significant effects on ulnar nerve strain. However, only four embalmed elbows were studied in this preliminary study, so a large difference would be needed to produce a significant change. The finding that medial epicondylectomy fails to reduce strain raises questions about its role in treating cubital tunnel syndrome and highlights the need for further research.

\section{Recommendation}

While this study has highlighted the need for further research into a multitude of areas, the authors believe that the technique described for dynamic strain assessment is applicable to an in vivo setting and therefore, should be used to compare strain properties of cadaveric and in vivo nerves.

\section{Ethical consideration and statement of the Declaration of Helsinki}

For the porcine pilot study, ethical approval was obtained from the University of Birmingham (license: 'Porcine limb nerve tissue', ERN_16-1592). For the cadaveric study, ethical approval was granted by the Human Tissue Authority according to the Human Tissue Act, ${ }^{[41]}$ and informed consent for education and research was obtained from all donors prior to death as part of the donor registration programme at the University of Birmingham (license number 12236). Therefore, this experiment has been performed in accordance with the 1964 Declaration of Helsinki and all subsequent revisions.

\section{Acknowledgements}

The authors would like to express their gratitude to the donors and their families for their altruistic donation to medical education and research. The authors would also like to thank Linda Molanga, Nikita Maria, Max Roderick, Howard Stringer, Priyesh Chauhan and Peter Gaskell for allowing this experiment to be conducted on the cadavers that they were dissecting. Finally, the authors would like to thank Martin Jones, Vicky Cottrell, Amanda Abbott, Kevan Charlesworth, Jack Garrod, Lee Gauntlett, Pete Thornton and Mark Wager for their assistance during dissection and testing.

\section{Financial support and sponsorship}

Nil.

\section{Conflicts of interest}

There are no conflicts of interest.

\section{Author's contribution}

CGB assisted in dissecting the arms and performing the medial epicondylectomy operation as well as with photography, ImageJ software and statistical analysis. TC, DMP and ST assisted in dissecting the arms, performing the 
Barberio, et al.

medial epicondylectomy operation as well as teaching these techniques to CGB and helping to conduct the experiment. BML and DME assisted in the mechanical design and conduct of the experiment as well as with photography, ImageJ software and statistical analysis. JCW facilitated the identification and organisation of this project as well as assisting in dissection and teaching the necessary techniques to CGB. All authors assisted in the final write-up and submission. All authors testify that all persons designated as authors qualify for authorship. All authors have critically reviewed and approved the final draft and are responsible for the content and similarity index of the manuscript.

\section{REFERENCES}

1. Assmus H, Antoniadis G, Bischoff C, Hoffman R, Martini AK, Preißler $\mathrm{P}$, et al. Diagnosis and therapy of the cubital tunnel syndrome. MF Guidelines Register No. 005/009 | Development stage 3. IDA; 2008.

2. Naran S, Imbriglia JE, Bilonick RA, Taieb A, Wollstein R. A demographic analysis of cubital tunnel syndrome. Ann Plast Surg 2010;64:177-9.

3. Bozentka DJ. Cubital tunnel syndrome. Clin Biomech 1988;351:90-4.

4. Apfelberg DB, Larson SJ. Dynamic anatomy of the ulnar nerve at the elbow. Plast Reconstr Surg 1973;51:79-81.

5. Gelberman RH, Yamaguchi K, Hollstien SB, Winn SS, Heidenreich FP Jr., Bindra RR, et al. Changes in interstitial pressure and cross-sectional area of the cubital tunnel and of the ulnar nerve with flexion of the elbow. An experimental study in human cadavera. J Bone Joint Surg Am 1998;80:492-501.

6. James J, Sutton LG, Werner FW, Basu N, Allison MA, Palmer AK, et al. Morphology of the cubital tunnel: An anatomical and biomechanical study with implications for treatment of ulnar nerve compression. J Hand Surg Am 2011;36:1988-95.

7. Schuind FA, Goldschmidt D, Bastin C, Burny F. A biomechanical study of the ulnar nerve at the elbow. J Hand Surg Br 1995;20:623-7.

8. Toby EB, Hanesworth D. Ulnar nerve strains at the elbow. J Hand Surg Am 1998;23:992-7.

9. Wright TW, Glowczewskie F Jr., Cowin D, Wheeler DL. Ulnar nerve excursion and strain at the elbow and wrist associated with upper extremity motion. J Hand Surg Am 2001;26:655-62.

10. Lundborg G, Rydevik B. Effects of stretching the tibial nerve of the rabbit. A preliminary study of the intraneural circulation and the barrier function of the perineurium. J Bone Joint Surg Br 1973;55:390-401.

11. Ogata K, Naito M. Blood flow of peripheral nerve effects of dissection, stretching and compression. J Hand Surg Br 1986;11:10-4.

12. Clark WL, Trumble TE, Swiontkowski MF, Tencer AF. Nerve tension and blood flow in a rat model of immediate and delayed repairs. J Hand Surg Am 1992;17:677-87.

13. Wall EJ, Massie JB, Kwan MK, Rydevik BL, Myers RR, Garfin SR, et al. Experimental stretch neuropathy. Changes in nerve conduction under tension. J Bone Jt Surg Br 1992;74:126-9.

14. Aoki M, Takasaki H, Muraki T, Uchiyama E, Murakami G, Yamashita T, et al. Strain on the ulnar nerve at the elbow and wrist during throwing motion. J Bone Joint Surg Am 2005;87:2508-14.

15. Ochi K, Horiuchi Y, Horiuchi K, Iwamoto T, Morisawa Y, Sato K, et al. Shoulder position increases ulnar nerve strain at the elbow of patients with cubital tunnel syndrome. J Shoulder Elbow Surg 2015;24:1380-5.

16. Hicks D, Toby EB. Ulnar nerve strains at the elbow: The effect of in situ decompression and medial epicondylectomy. J Hand Surg Am 2002;27:1026-31.

17. Mitchell J, Dunn JC, Kusnezov N, Bader J, Ipsen DF, Forthman CL, et al. The effect of operative technique on ulnar nerve strain following surgery for cubital tunnel syndrome. Hand (N Y) 2015;10:707-11.

18. Cirpar M, Turker M, Yalcinozan M, Eke M, Sahin F. Effect of partial, distal epicondylectomy on reduction of ulnar nerve strain: A cadaver study. J Hand Surg Am 2013;38:666-71

19. Byl C, Puttlitz C, Byl N, Lotz J, Topp K. Strain in the median and ulnar nerves during upper-extremity positioning. J Hand Surg Am 2002;27:1032-40.

20. Coppieters MW, Butler DS. Do 'sliders' slide and 'tensioners' tension? An analysis of neurodynamic techniques and considerations regarding their application. Man Ther 2008;13:213-21.

21. Novak CB, Mehdian H, von Schroeder HP. Laxity of the ulnar nerve during elbow flexion and extension. J Hand Surg Am 2012;37:1163-7.

22. Ochi K, Horiuchi Y, Nakamura T, Sato K, Arino H, Koyanagi T. Ulnar nerve strain at the elbow in patients with cubital tunnel syndrome: effect of simple decompression. J Hand Surg Eur Vol 2012;38:474-80.

23. Mahan MA, Vaz KM, Weingarten D, Brown JM, Shah SB. Altered ulnar nerve kinematic behavior in a cadaver model of entrapment. Neurosurgery 2015;76:747-55.

24. Foran I, Vaz K, Sikora-Klak J, Ward SR, Hentzen ER, Shah SB, et al. Regional ulnar nerve strain following decompression and anterior subcutaneous transposition in patients with cubital tunnel syndrome. J Hand Surg Am 2016;41:e343-50.

25. Jones RE, GaunttC. Medial epicondylectomy for ulnar nerve compression syndrome at the elbow. Clin Orthop Relat Res 1979;139:174-8.

26. Ma Z, Hu S, Tan JS, Myer C, Njus NM, Xia Z, et al. In vitro and in vivo mechanical properties of human ulnar and median nerves. J Biomed Mater Res A 2013;101:2718-25.

27. Kaempffe FA, Farbach J. A modified surgical procedure for cubital tunnel syndrome: Partial medial epicondylectomy. J Hand Surg Am 1998;23:492-9.

28. Schneider CA, Rasband WS, Eliceiri KW. NIH image to ImageJ: 25 years of image analysis. Nat Methods 2012;9:671-5.

29. Schindelin J, Rueden CT, Hiner MC, Eliceiri KW. The ImageJ ecosystem: An open platform for biomedical image analysis. Mol Reprod Dev 2015;82:518-29.

30. Meijering E, Dzyubachyk O, Smal I. Methods for cell and particle tracking. Methods Enzymol 2012;504:183-200.

31. Kim KW, Lee HJ, Rhee SH, Baek GH. Minimal epicondylectomy improves neurologic deficits in moderate to severe cubital tunnel syndrome. Clin Orthop Relat Res 2012;470:1405-13.

32. Kleinrensink GJ, Stoeckart R, Vleeming A, Snijders CJ, Mulder PG, van Wingerden JP, et al. Peripheral nerve tension due to joint motion. A comparison between embalmed and unembalmed human bodies. Clin Biomech (Bristol, Avon) 1995; 10:235-9.

33. Ochi K, Horiuchi Y, Nakamura T, Sato K, Morita K, Horiuchi K, et al. Associations between ulnar nerve strain and accompanying conditions in patients with cubital tunnel syndrome. Hand Surg 2014;19:329-33.

34. Barberio CG, Chaudhry T, Power DM, Tan S, Lawless BM, Espino DM, et al. Towards viscoelastic characterisation of the human ulnar nerve: An early assessment using embalmed cadavers. Med Eng Phys 2018. pii: S1350-4533(18)30178-4.

35. Goldberg BJ, Light TR, Blair SJ. Ulnar neuropathy at the elbow: Results of medial epicondylectomy. J Hand Surg Am 1989;14:182-8.

36. Heithoff SJ, Millender LH, Nalebuff EA, Petruska AJ Jr. Medial epicondylectomy for the treatment of ulnar nerve compression at the elbow. J Hand Surg Am 1990;15:22-9.

37. Froimson AI, Anouchi YS, Seitz WH Jr., Winsberg DD. Ulnar nervedecompression with medial epicondylectomy for neuropathy at the elbow. Clin Orthop Relat Res 1991;265:200-6.

38. Steere AC, Hall WJ $3^{\text {rd }}$, Wells JG, Craven PJ, Leotsakis N, Farmer JJ $3^{\text {rd }}$, et al. Person-to-person spread of salmonella typhimurium after a hospital common-source outbreak. Lancet 1975;1:319-22.

39. Schnabl SM, Kisslinger F, Schramm A, Dragu A, Kneser U, Unglaub F, et al. Subjective outcome, neurophysiological investigations, postoperative complications and recurrence rate of partial medial epicondylectomy in cubital tunnel syndrome. Arch Orthop Trauma Surg 2011;131:1027-33.

40. Osei DA, Padegimas EM, Calfee RP, Gelberman RH. Outcomes following modified oblique medial epicondylectomy for treatment of cubital tunnel syndrome. J Hand Surg Am 2013;38:336-43.

41. Human Tissue Act. Subsection 3, Part 1. 2004. 